\title{
MTOR downregulates iodide uptake in thyrocytes
}

\author{
Elaine Cristina Lima de Souza ${ }^{1}$, Álvaro Souto Padrón', William Miranda Oliveira Braga ${ }^{\text {, }}$ \\ Bruno Moulin de Andrade ${ }^{1}$, Mário Vaisman ${ }^{2}$, Luiz Eurico Nasciutti ${ }^{3}$, Andrea Claudia Freitas Ferreira ${ }^{1}$ \\ and Denise Pires de Carvalho ${ }^{1}$ \\ ${ }^{1}$ Laboratório de Fisiologia Endócrina Doris Rosenthal, Instituto de Biofísica Carlos Chagas Filho, ${ }^{2}$ Serviço de Endocrinologia, Hospital Universitário Clementino \\ Fraga Filho and ${ }^{3}$ Laboratório de Interações Celulares do Programa de Pesquisa em Biologia Celular e do Desenvolvimento, Instituto de Ciências Biomédicas, \\ Universidade Federal do Rio de Janeiro, Rio de Janeiro 21949-900, Brazil \\ (Correspondence should be addressed to D P de Carvalho; Email: dencarv@biof.ufrj.br)
}

\begin{abstract}
Phosphoinositide-3-kinase (PI3K) inhibition increases functional sodium iodide symporter (NIS) expression in both FRTL-5 rat thyroid cell line and papillary thyroid cancer lineages. In several cell types, the stimulation of PI3K results in downstream activation of the mechanistic target of rapamycin (MTOR), a serine-threonine protein kinase that is a critical regulator of cellular metabolism, growth, and proliferation. MTOR activation is involved in the regulation of thyrocyte proliferation by TSH. Here, we show that MTOR inhibition by rapamycin increases iodide uptake in TSH-stimulated PCCL3 thyroid cell line, although the effect of rapamycin was less pronounced than PI3K inhibition. Thus, NIS inhibitory pathways stimulated by PI3K might also involve the activation of proteins other than MTOR. Insulin downregulates iodide uptake and NIS protein expression even

in the presence of TSH, and both effects are counterbalanced by MTOR inhibition. NIS protein expression levels were correlated with iodide uptake ability, except in cells treated with TSH in the absence of insulin, in which rapamycin significantly increased iodide uptake, while NIS protein levels remained unchanged. Rapamycin avoids the activation of both p70 S6 and AKT kinases by TSH, suggesting the involvement of MTORC1 and MTORC2 in TSH effect. A synthetic analog of rapamycin (everolimus), which is clinically used as an anticancer agent, was able to increase rat thyroid iodide uptake in vivo. In conclusion, we show that MTOR kinase participates in the control of thyroid iodide uptake, demonstrating that MTOR not only regulates cell survival, but also normal thyroid cell function both in vitro and in vivo. Journal of Endocrinology (2010) 206, 113-120
\end{abstract}

\section{Introduction}

Iodide is transported across the basolateral membrane of thyroid follicular cells by the sodium iodide symporter (NIS; Dai et al. 1996), which is an integral plasma membrane glycoprotein that plays an essential role in thyroid physiology. The ability of the thyroid gland to accumulate radioiodine is also important for the diagnosis and treatment of thyroid disorders (Mazaferri 2000).

TSH is the major regulator of thyroid cell proliferation, differentiation, and function, including iodide uptake (Vassart \& Dumont 1992). The effects of TSH are primarily mediated via activation of adenylate cyclase by the $\alpha$-subunit of stimulatory GTP-binding protein (Gs $\alpha$; Laglia et al. 1996). TSH increases iodide accumulation by positively regulating NIS expression at the protein and mRNA levels via the cAMP pathway (Weiss et al. 1984). In FRTL-5 cells, withdrawal of TSH results in a decrease in intracellular cAMP concentration and iodide uptake (Weiss et al. 1984). Re-addition of TSH increases NIS mRNA and protein expression, and subsequently restores iodide uptake. Moreover, TSH might also regulate NIS activity by posttranslational mechanisms (Riedel et al. 2001); since in the presence of TSH, NIS is active and inserted at the basolateral membrane of thyrocytes; however, upon TSH withdrawal, NIS protein half-life decreases from 5 to 3 days, and it is suggested that the protein translocates from the plasma membrane to intracellular compartments (Riedel et al. 2001). The mechanisms regulating the subcellular distribution of NIS and its function have only been partially elucidated, although NIS has several consensus sites for kinases, including protein kinase A and protein kinase C (Dohan et al. 2003).

In thyrocytes, phosphatidyl-inositol-3-kinase (PI3K) pathway plays a central role in controlling both cell proliferation and differentiation. PI3K is activated in thyrocytes by many growth factors such as insulin/insulinlike growth factor 1 (IGF1), hepatocyte growth factor, or epidermal growth factor (Kimura et al. 2001). Apart from the cAMP pathway, TSH receptor activation also leads to PI3K activation. Treatment with PI3K inhibitors or the expression of a dominant-negative form of PI3K causes a $G_{1}$ arrest in rat thyroid cells stimulated to proliferate by TSH (Cass et al. 1999, Medina et al. 2000). Apart from that, it has been reported 
that PI3K is required for thyrocytes to proliferate under TSH stimulation (Coulonval et al. 2000). Concerning the differentiation of thyroid cells, the activation of PI3K by IGF1 inhibits the expression of NIS that is stimulated by TSH and cAMP (Garcia \& Santisteban 2002). Moreover, TSH stimulates AKT phosphorylation in a PI3K-dependent and cAMP-independent manner (Zaballos et al. 2008), which is mediated by the $G \beta \gamma$ dimer. G $\beta \gamma$ sequestration increases NIS protein levels induced by TSH and PAX-8 binding to the NIS promoter, which is also increased by the use of PI3K inhibitor (Zaballos et al. 2008).

The serine-threonine protein kinase mechanistic target of rapamycin (MTOR) is a critical regulator of cellular metabolism, growth, and proliferation (reviewed by Sarbassov et al. (2005a)). These processes contribute to tumor formation, and many cancers are characterized by aberrant activation of MTOR. Although activating mutations in MTOR itself have not been identified, deregulations of upstream components that control MTOR are prevalent in cancer. The prototypic mechanism of MTOR regulation in cells is through the activation of the PI3K/AKT pathway, but MTOR also receives input from multiple signaling pathways.

MTOR protein kinase has been described in two distinct multiprotein complexes that regulate different branches of the MTOR network. The MTOR complex 1 (MTORC1) consists of MTOR, raptor, and mLST8 (also known as G $\beta \mathrm{L}$ ), and regulates cell growth through effectors such as p70 S6K (also called S6K1) and 4E-binding protein 1 (4E-BP1). The MTOR complex 2 (MTORC2) contains MTOR, rictor, and mLST8, and phosphorylates AKT/protein kinase B (PKB) on S473 (Hresko \& Mueckler 2005, Sarbassov et al. 2005b). Together with T308 phosphorylation of AKT/PKB by PDK1, S473 phosphorylation is necessary for full AKT/ PKB activation (Alessi et al. 1996).

Since PI3K activation in thyrocytes inhibits NIS expression, we hypothesized that MTOR might be involved in NIS regulation. Our study aimed to evaluate the possible role of MTOR in the regulation of iodide uptake in PCCL3 thyroid cell line. We show herein that MTOR inhibition by rapamycin leads to a significant increase in iodide uptake in TSH-stimulated thyroid PCCL3 cells, and also in normal rat thyroids in vivo.

\section{Materials and Methods}

\section{Materials}

TSH, insulin, transferrin, hydrocortisone, somatostatin, glycyl-L-histidyl-L-lysine acetate, rapamycin, and LY294002 were purchased from Sigma. Specific antibodies against the total and phosphorylated forms of AKT and p70 S6 kinase were purchased from Cell Signaling Technology Inc. (Beverly, MA, USA). Anti-NIS antibody was a generous gift from Dr Roberto Di Lauro (Stazione Zoologica Anton Dohrn, Naples, Italy). Everolimus was purchased from Novartis.

\section{Cell culture}

PCCL3 cells (donated by Prof. Roberto Di Lauro, Stazione Zoologica Anton Dohrn) were maintained in Coon's modified Ham's F-12 medium supplemented with 5\% fetal bovine serum and a six-hormone mixture $(1 \mathrm{mU} / \mathrm{ml}$ $\mathrm{TSH}, \quad 10 \mu \mathrm{g} / \mathrm{ml}$ insulin, $5 \mu \mathrm{g} / \mathrm{ml}$ transferrin, $10 \mathrm{nM}$ hydrocortisone, $10 \mathrm{ng} / \mathrm{ml}$ somatostatin, and $10 \mathrm{ng} / \mathrm{ml}$ glycyl-L-histidyl-L-lysine acetate; complete medium (Venkataraman et al. 1999)). The effect of hormones and kinase inhibitors was studied using near-confluent cells in the absence of TSH and insulin, in the presence of $0 \cdot 2 \%$ serum (starving medium) for $72 \mathrm{~h}$. The MTOR inhibitor, rapamycin, was added to cell cultures $1 \mathrm{~h}$ before hormone addition at the following concentrations: 10, 25, 100, 200, and $400 \mathrm{nM}$. The PI3K inhibitor, LY294002, was added to cells $1 \mathrm{~h}$ before hormone addition at a concentration of $10 \mu \mathrm{M}$. Similar results were obtained even if rapamycin or LY294002 was added together with TSH (data not shown). Cells were treated for $48 \mathrm{~h}$ with the inhibitor. In all experiments, control cells were cultivated in the presence of vehicle $(0 \cdot 01 \%$ dimethyl sulfoxide (DMSO)). For AKT and p70 S6 kinase evaluation, cells were treated as described above, except that rapamycin was added 20 min before TSH. After 20 min of treatment, cells were lysed for protein extraction and western blotting assays.

\section{Iodide uptake assay}

Iodide uptake assay was performed as described by Venkataraman et al. (1999), with some modifications. Briefly, $10^{5}$ PCCL3 cells grown in 24-well dishes, in the different assay conditions, were incubated for $45 \mathrm{~min}$ at $37^{\circ} \mathrm{C}$ with $1 \mathrm{ml}$ Hank's balanced salt solution (HBSS) containing $\sim 0 \cdot 1 \mu \mathrm{Ci}$ carrier-free $\mathrm{Na}^{125} \mathrm{I}$ and $100 \mu \mathrm{M}$ NaI. For each experimental condition, some wells received $10 \mu \mathrm{M} \mathrm{KClO}_{4}$, a competitive inhibitor of NIS, in order to determine the nonspecific radioiodide uptake. After the incubation, cells were washed once with ice-cold HBSS and lysed with $0 \cdot 1 \mathrm{M}$ $\mathrm{NaOH}$, and radioactivity was measured in a gamma-counter. A parallel set of dishes, similarly plated and treated, was used for normalization of iodide uptake, using the 3-(4,5-dimethylthiazol-2-yl)-2,5-diphenyltetrazolium bromide (MTT) assay as an index of cell viability, as described below (Unterholzner et al. 2006). Specific iodide uptake value was obtained by subtracting iodide uptake in the absence and in the presence of $\mathrm{KClO}_{4}$ and related to cell viability. Results are expressed as specific units of iodide accumulation relative to control.

\section{Iodide efflux assay}

The procedure was performed as previously described (Brewer et al. 2007). Briefly, $10^{5}$ PCCL3 cells grown in 24-well dishes were incubated with $1 \mathrm{ml}$ HBSS containing $\sim 0 \cdot 1 \mu \mathrm{Ci}$ carrier-free $\mathrm{Na}^{125} \mathrm{I}$ and $100 \mu \mathrm{M} \mathrm{NaI}$ for $45 \mathrm{~min}$. Then, medium was removed and replaced with fresh HBSS without $\mathrm{NaI}$, the procedure repeated every $3 \mathrm{~min}$ until 
$12 \mathrm{~min}$. The content of ${ }^{125} \mathrm{I}$ in the collected supernatant was measured in a gamma-counter. After the last time point (12 min), cells were lysed with $500 \mu \mathrm{l}$ of $0 \cdot 1 \mathrm{M} \mathrm{NaOH}$ to measure the residual intracellular radioactivity.

\section{Cell viability assay}

As an index of cell viability, we used the commercially available MTT assay (Sigma-Aldrich) according to the manufacturer's recommendations. This is a colorimetric assay to determine the number of viable cells. The assay is based on the cellular conversion of the tetrazolium salt into formazan that is soluble in tissue culture medium, and is measured directly at $490 \mathrm{~nm}$ in 96-well assay plates. Absorbance is directly proportional to the number of living cells in culture. PCCL3 cells were seeded and cultured with F12 medium, in the same conditions of the cells cultivated for analysis of iodide uptake assay. After treatment, cells were stained with MTT $(0.5 \mathrm{mg} / \mathrm{ml})$ for $3 \mathrm{~h}$ at $37^{\circ} \mathrm{C}$ in a humidified $5 \% \mathrm{CO}_{2}$ atmosphere. Then, cells were lysed with DMSO (P A). All determinations were done in triplicates.

Immunoblotting of NIS, p70 S6K, phospho-p $70 \mathrm{~S} 6 \mathrm{~K}, A K T$, and phospho- $A K T$

PCCL3 cells were homogenized in lysis buffer containing $135 \mathrm{mM} \mathrm{NaCl}, 1 \mathrm{mM} \mathrm{MgCl} 2,2 \cdot 7 \mathrm{mM} \mathrm{KCl}, 20 \mathrm{mM}$ Tris, $\mathrm{pH} 8 \cdot 0,1 \%$ Triton, $10 \%$ glycerol, and protease and phosphatase inhibitors $\left(0.5 \mathrm{mM} \mathrm{Na}_{3} \mathrm{VO}_{4}, 10 \mathrm{mM} \mathrm{NaF}, 1 \mathrm{M}\right.$ leupeptin, $1 \mathrm{M}$ pepstatin, $1 \mathrm{M}$ okadaic acid, and $0.2 \mathrm{mM}$ phenylmethylsulfonyl fluoride), and then syringed five times. Subsequently, the vials were centrifuged, and the supernatant was collected. An aliquot was used to determine the concentration of protein by BCA protein assay kit (Pierce, Rockford, IL, USA, catalog number 23227 ) as described by the manufacturer. The protein was then subjected to SDS/PAGE electrophoresis, transferred to PVDF membranes, and probed with the indicated antibodies. The detection of the proteins was performed using ECL.

\section{Animals}

Adult male Wistar rats weighing around $200 \mathrm{~g}$ were housed under controlled conditions of temperature $\left(24 \pm 1^{\circ} \mathrm{C}\right)$ and light $(12 \mathrm{~h}$ light starting at $0700 \mathrm{~h})$ with water and food offered ad libitum. The study conforms to the Guide for the Care and Use of Laboratory Animals published by the US National Institutes of Health (NIH Publication No. 85-23, revised 1996), and was approved by the Institutional Animal Welfare Committee (CAUAP/UFRJ).

\section{Animal treatment and determination of in vivo iodide uptake by the thyroid gland}

The in vivo thyroid iodide uptake was performed as previously described (Ferreira et al. 2005) with minor modifications. Everolimus was administered by oral gavage at four doses of
$5 \mathrm{mg} / \mathrm{kg}$ body weight, $24,8,4$, and $2 \mathrm{~h}$ before radioiodide administration, totaling $20 \mathrm{mg} / \mathrm{kg}$ body weight in $24 \mathrm{~h}$. Then, animals received $\left[{ }^{125} \mathrm{I}\right] \mathrm{NaI}(3700 \mathrm{~Bq}$, i.p., Amersham) $15 \mathrm{~min}$ prior to decapitation. Thyroids were removed and weighed, and their radioactivity was measured using a gamma-counter. Iodide uptake was expressed as percentage of total ${ }^{125} \mathrm{I}$ injected per $\mathrm{mg}$ of thyroid, relative to control.

\section{Statistical analysis}

Results are expressed as means \pm S.E.M., and were analyzed by two-way ANOVA, followed by Bonferroni's multiple comparison tests. In vivo results were analyzed by Mann-Whitney test. Dose-response curve of rapamycin and iodide efflux was analyzed by the Kruskal-Wallis ANOVA followed by the Dunn multiple comparison tests. Differences were considered significant when $P<0 \cdot 05$.

\section{Results}

Effect of MTOR pathway inhibition by rapamycin on iodide uptake in PCCL3 cells

In order to evaluate the importance of MTOR in NIS regulation we used a specific inhibitor of MTOR, rapamycin. We treated PCCL3 cells, in the presence of TSH and in the absence of insulin, with different concentrations of rapamycin. After $48 \mathrm{~h}$, a dose-dependent stimulation of iodide uptake by rapamycin was observed in the presence of TSH. We have already observed an increase in iodide uptake at the concentration of $25 \mathrm{nM}$, but it was significant at the concentration of $50 \mathrm{nM}$ and higher. The maximum effect on iodide uptake was detected at the dose of $100 \mathrm{nM}$ rapamycin (Fig. 1). In TSH-stimulated cells, $100 \mathrm{nM}$ rapamycin increased iodide uptake by $\sim 1.4$-fold in the absence of insulin. Iodide uptake was not affected by treatment with $100 \mathrm{nM}$ of rapamycin for $4 \mathrm{~h}$ (data not shown), suggesting that rapamycin requires a longer period of time to produce its effect.

Effects of TSH, insulin, and rapamycin on iodide uptake and efflux

Since TSH is the most important regulator of iodide uptake, we tested whether the rapamycin effect depends on the presence of TSH. Cells were maintained in starving medium (without TSH and insulin) for 3 days, and were then treated for $48 \mathrm{~h}$ in the presence or in the absence of $\mathrm{TSH}$, insulin, and rapamycin. Iodide uptake decreases approximately eightfold in the absence of TSH, and MTOR inhibition with rapamycin $(100 \mathrm{nM})$ significantly increased iodide uptake only in TSH-stimulated PCCL3 cells (Fig. 2A). Insulin was noted to inhibit iodide uptake 


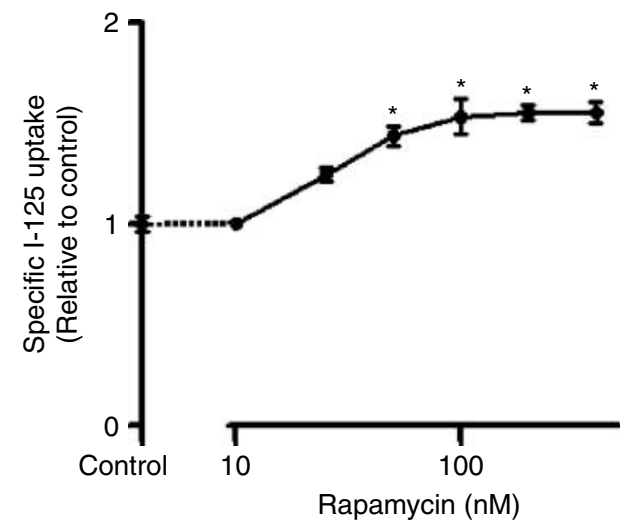

Figure 1 Dose-response curve of MTOR inhibitor rapamycin on TSH-induced iodide uptake in PCCL3 cells. Cells grown in 24-well plates were treated with rapamycin $(10,25,50,100,200$, and $400 \mathrm{nM}$ ) for $48 \mathrm{~h}$, in the presence of $1 \mathrm{mU} / \mathrm{ml} \mathrm{TSH}$ and in the absence of insulin. PCCL3 cells were cultivated in the presence of $0 \cdot 2 \% \mathrm{FBS}$ and in the absence of TSH and insulin for 3 days prior to the treatment with rapamycin and TSH. Rapamycin was added $1 \mathrm{~h}$ before TSH addition. Values represent the results of three independent experiments, and are expressed as mean \pm S.E.M. $(n=6) .{ }^{*} P<0.05$ vs 0,10 , and $25 \mathrm{nM}$ rapamycin.

by three- to fourfold in cells treated with TSH, but the stimulatory effect of rapamycin was still apparent relative to vehicle (Fig. 2A). This result indicates that TSH, independently of insulin, is able to activate MTOR, and that insulin inhibits the stimulatory effect of TSH on iodide uptake by at least two different pathways, one dependent on and the other independent of MTOR.

We then evaluated the possibility that insulin and rapamycin could also modulate iodide efflux. We observed that neither insulin nor rapamycin affected iodide efflux (Fig. 2B). These data indicate that the modulation of intracellular iodide content observed in the PCCL3 cells treated with insulin and rapamycin is due to NIS regulation.

\section{Effects of TSH, insulin, and rapamycin on NIS expression}

We then evaluated the effect of rapamycin on NIS protein expression. In the absence of TSH, NIS expression was low (Fig. 3, lane 1), and insulin was able to further decrease NIS expression (Fig. 3, lane 3). In the absence of TSH, NIS expression was not affected by rapamycin treatment (Fig. 3, lanes 2-4). NIS protein expression paralleled iodide uptake measurements.

The highest level of NIS protein expression was detected in cells treated with TSH in the absence of insulin (Fig. 3, lane 5). Rapamycin did not promote a further increase in the expression of NIS in this condition, even though rapamycin was able to significantly increase iodide uptake. Insulin significantly decreased NIS expression (Fig. 3, lane 7), which was counterbalanced by rapamycin that was able to restore NIS expression (Fig. 3, lane 8).
Comparison between the effects of MTOR and PI3K pathway inhibition by rapamycin and LY294002 respectively on iodide uptake in PCCL3 cells

Our objective was to compare the effects of PI3K inhibition by LY294002 with MTOR inhibition by rapamycin on iodide uptake. PI3K inhibition (LY294002, $10 \mu \mathrm{M}$ ) increased iodide uptake by $\sim 2 \cdot 5$-fold in the absence of insulin, while MTOR inhibition increased $\sim 1 \cdot 5$-fold (Fig. 4). The increase in iodide uptake was more pronounced by PI3K inhibition, even using the maximum concentration of rapamycin; these results suggest that PI3K might also inhibit NIS through pathways other than MTOR. In the absence of TSH, neither MTOR nor PI3K inhibition was able to increase iodide uptake in PCCL3 cells (data not shown). In the presence of insulin, LY294002 and rapamycin also increased iodide uptake, but the effect was not as intense as observed in the absence of insulin. These results reinforce the hypothesis that insulin inhibits iodide uptake also by other pathways apart from PI3K and MTOR.
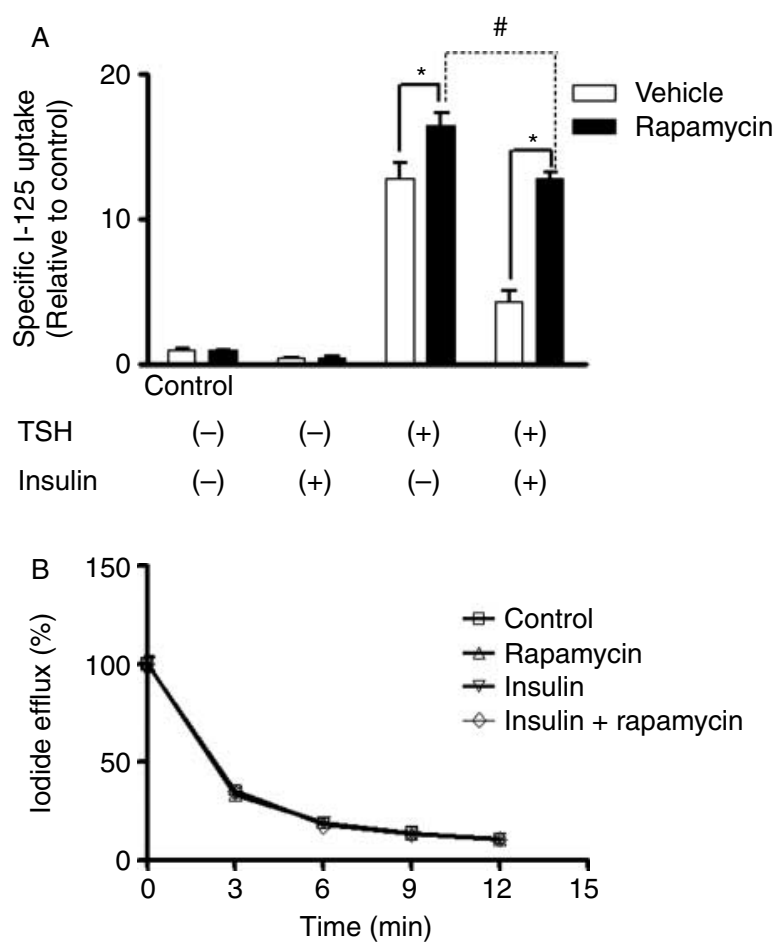

Figure 2 Effect of MTOR inhibition by rapamycin on iodide uptake and efflux in PCCL3 cells. Cells maintained in starving medium (without TSH and insulin) for 3 days were treated with $1 \mathrm{mU} / \mathrm{ml} \mathrm{TSH}$ and/or $10 \mathrm{mg} / \mathrm{ml}$ insulin, in the presence or in the absence of $100 \mathrm{nM}$ rapamycin for $48 \mathrm{~h}$. Rapamycin was added $1 \mathrm{~h}$ before hormone treatments. Control cells were treated with vehicle $(0 \cdot 01 \%$ dimethyl sulfoxide). (A) lodide uptake in PCCL3 cells treated with or without rapamycin and/or insulin. Values represent the results of two independent experiments, and are expressed as mean \pm S.E.M. $(n=9)$. ${ }^{*} P<0 \cdot 05$ vehicle versus rapamycin-treated cells. ${ }^{\#} P<0 \cdot 05$ rapamycin + TSH versus rapamycin + TSH + insulin. (B) lodide efflux in PCCL3 cells treated with or without rapamycin and/or insulin. Values represent the results of three independent experiments, and are expressed as mean \pm S.E.M. $(n=9)$. ${ }^{*} P<0 \cdot 05$ versus control. 


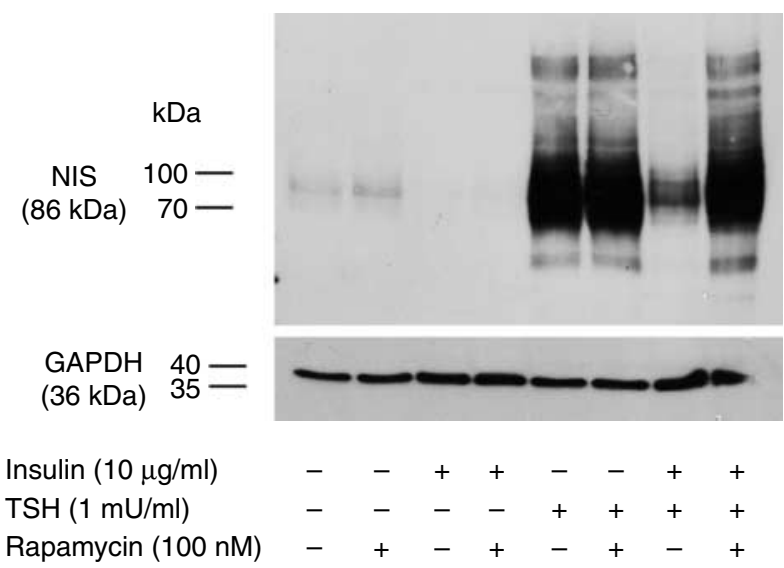

Figure 3 Effect of MTOR inhibition by rapamycin on NIS protein expression. Cells maintained in starving medium (without TSH and insulin) for 3 days were treated with $1 \mathrm{mU} / \mathrm{ml} \mathrm{TSH}$ and/or $10 \mathrm{mg} / \mathrm{ml}$ insulin, in the presence or in the absence of $100 \mathrm{nM}$ rapamycin for $48 \mathrm{~h}$. Rapamycin was added $1 \mathrm{~h}$ before hormone treatments. Control cells were treated with vehicle $(0 \cdot 01 \%$ dimethyl sulfoxide). Whole cell lysates were prepared, and western blot analysis was performed with $30 \mu \mathrm{g}$ protein using anti-rat NIS antibody, as well as anti-GAPDH antibody.

\section{Effect of TSH on $p 70$ S6 and AKT phosphorylations in PCCL3 cells}

In order to evaluate MTOR activation by TSH, we analyzed p70 S6 and AKT phosphorylations. In several cell types, MTOR is present in two complexes, MTORC1 and MTORC2. While MTORC1 activates p70 S6 kinase and regulates translation signals, MTORC2 activates AKT in Ser473 and regulates cell apoptosis and survival.

Cells were maintained in starving medium (without TSH and insulin) for 3 days, and were then treated for $20 \mathrm{~min}$ in the presence or in the absence of TSH and rapamycin. Rapamycin was added $20 \mathrm{~min}$ before TSH treatment. After 3 days in starving conditions, p70 S6 and AKT kinases were not phosphorylated (Fig. 5). After $20 \mathrm{~min}$ in the presence of TSH, we detected the phosphorylation of both kinases, and rapamycin was able to completely avoid the activation of p70 S6K, and also part of AKT activation (Fig. 5).

\section{Inhibition of MTOR kinase decreases cell viability in PCCL3 cells}

It is known that MTOR pathway has important survival and anti-apoptotic effects. So, we evaluated cellular viability after rapamycin treatment. Insulin is as important for cell viability as TSH, and there is a synergistic effect between TSH and insulin in the regulation of cell viability (Fig. 6). MTOR inhibition significantly decreased cellular viability by $30 \%$ in the presence of insulin and/or TSH (Fig. 6). Interestingly, in the absence of these hormones, rapamycin had no effect on cell viability.
Effect of a synthetic analog of rapamycin on iodide uptake in vivo

Apart from the effects of rapamycin on PCCL3 cell iodide uptake ability and viability in vitro, we also studied the effect of MTOR inhibition in vivo. Everolimus, an orally active rapalog (rapamycin analog), has been tested in several phase I and II clinical trials. Similar to what was observed in PCCL3 cells, in vivo $\mathrm{MTOR}$ inhibition significantly increased thyroid iodide uptake by $\sim 50 \%$ related to control (Fig. 7). Moreover, thyroid weight was not significantly reduced (data not shown). These results provide evidence that MTOR inhibition not only regulates iodide uptake in vitro but also in vivo.

\section{Discussion}

We show herein that MTOR inhibition increases NIS expression in PCCL3 thyroid cells cultivated in the presence of insulin and TSH, leading to higher iodide uptake ability. Our data differ from the results obtained using a PI3K inhibitor, LY294002, in FRTL-5 thyroid cells, in which LY294002 increased iodide uptake independent of TSH (Kogai et al. 2008). Rapamycin increased iodide uptake, although to a lesser extent than LY294002. It is interesting to note that in the presence of insulin, neither rapamycin nor LY294002 restored iodide uptake to the levels observed in the absence of insulin. These results suggest that insulin might also inhibit iodide uptake through pathways other than PI3K and MTOR. In insulin-treated cells, the increase in iodide uptake induced by rapamycin seems to be dependent on the upregulation of NIS protein, while posttranslational regulation is likely important in the insulin-deprived cells, since rapamycin treatment increased iodide uptake, but not NIS expression. These results corroborate with others, in which LY294002 only affected NIS protein expression in the presence of insulin (Kogai et al. 2008).

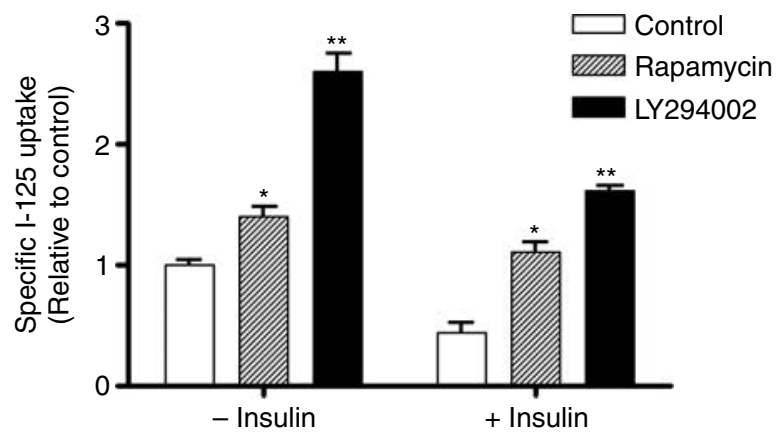

Figure 4 Comparison between the effects of MTOR and PI3K inhibition by rapamycin and LY294002 respectively on iodide uptake in PCCL3 cells. Cells maintained in starving medium (without TSH and insulin) for 3 days were treated with $1 \mathrm{mU} / \mathrm{ml}$ $\mathrm{TSH}$ in the presence or in the absence of $10 \mathrm{mg} / \mathrm{ml}$ insulin, $100 \mathrm{nM}$ rapamycin, and $10 \mu \mathrm{M}$ LY294002 for 48 h. Rapamycin or LY294002 was added $1 \mathrm{~h}$ before hormone treatments. Control cells were treated with vehicle $(0 \cdot 01 \%$ dimethyl sulfoxide). Values are expressed as mean \pm S.E.M. $(n=6)$. ${ }^{*} P<0 \cdot 05$ versus control, ${ }^{* *} P<0.05$ versus control and versus rapamycin. 


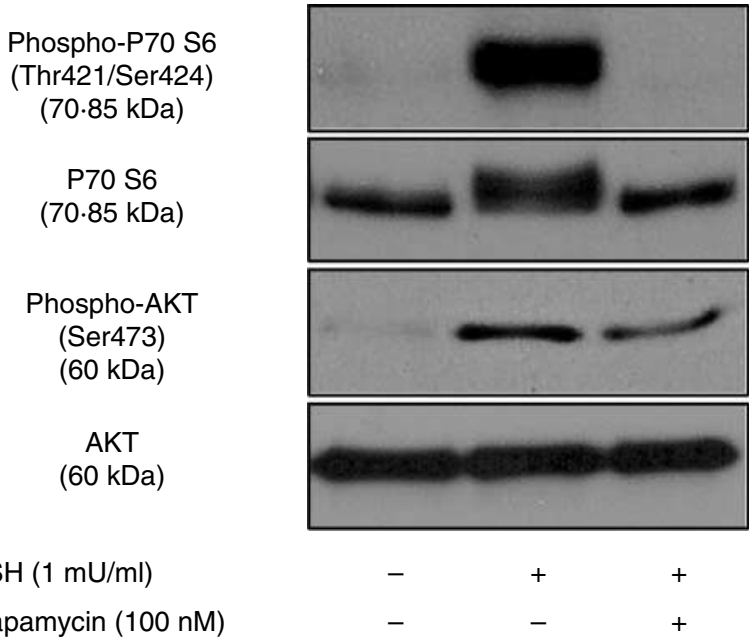

Rapamycin (100 nM)

Figure 5 Effect of MTOR inhibition on p70 S6 and AKT protein expression and phosphorylation in PCCL3 cells treated in the presence or in the absence of TSH and rapamycin. Cells maintained in starving medium (without TSH and insulin) for 3 days were treated with $1 \mathrm{mU} / \mathrm{ml} \mathrm{TSH}$ in the presence or in the absence of $100 \mathrm{nM}$ rapamycin for $20 \mathrm{~min}$. Rapamycin was added $20 \mathrm{~min}$ before TSH administration. Control cells were treated with vehicle $(0 \cdot 01 \%$ dimethyl sulfoxide). Whole cell lysates were prepared, and western blot analysis was performed with $30 \mu \mathrm{g}$ protein using anti-p70 S6 kinase, phospho-p70 S6 (Thr421/Ser424), AKT, and phospho-AKT (Ser473) antibodies.

The view that thyroid iodide uptake is primarily regulated by TSH has recently been expanded by the notion that IGF1/PI3K axis also exerts an important regulatory role on thyroid iodide uptake (Garcia \& Santisteban 2002, Kogai et al. 2008). Previous studies have shown that IGF1 reduces TSH/ forskolin-induced NIS mRNA and protein levels, and this effect is PI3K mediated, since its specific inhibitor, LY294002, prevents IGF1 inhibition of NIS induction (Garcia \& Santisteban 2002). Also, LY294002 significantly enhances iodide uptake in two rat thyroid cell lines, FRTL-5 and PCCL3 (Kogai et al. 2008).

The immediate downstream effector of PI3K signaling is the PKB (also named AKT), which regulates cellular processes such as proliferation, survival, cell size, and mRNA translation (Bellacosa et al. 2005). Activated AKT has many substrates within the cell, such as TSC2 and PRAS40, leading to the activation of MTOR. However, an AKT-independent pathway can also stimulate MTOR.

AKT is activated by phospholipid binding and loop phosphorylation at Thr308 by PDK1 (Alessi et al. 1996) and by phosphorylation at Ser473. The previously elusive PDK2 responsible for phosphorylation of AKT at Ser 473 has been identified as being MTOR in a rapamycin-insensitive complex with rictor and Sin1 (MTORC2; Sarbassov et al. $2005 \mathrm{~b}$ ). AKT also plays a critical role in cell growth by directly phosphorylating MTOR in a rapamycin-sensitive complex containing raptor (MTORC1; Navé et al. 1999). More importantly, AKT phosphorylates and inactivates tuberin (TSC2), an inhibitor of MTOR within the MTORC1 (Inoki et al. 2002). Inhibition of MTOR stops protein synthesis machinery by inactivating p70 S6 kinase and activating the eukaryotic initiation factor 4E-BP1, an inhibitor of translation (Inoki et al. 2002, Manning et al. 2002).

We showed herein that TSH stimulates phospho-p70 S6 kinase in PCCL3 cells, and that rapamycin avoided this stimulation. These results corroborate with prior studies using mice thyrocytes in primary cultures (Brewer et al. 2007). Thus, we have shown that TSH stimulates AKT phosphorylation in serine 473 in PCCL3 cells, as also described in the rat WRT cell model (Cass et al. 1999) and in rat PCCL3 cells by other authors (Zaballos et al. 2008). On the other hand, in mice and dog thyrocytes in primary cultures (Coulonval et al. 2000, Brewer et al. 2007) and in rat FRTL-5 cells (Suh et al. 2003), TSH was not able to induce AKT phosphorylation. At present, we cannot rule out the reasons that might justify these discrepancies, and we cannot exclude the possibility of different molecular characteristics of the in vitro systems.

Rapamycin binds to the intracellular protein FKBP12 to generate a drug-receptor complex that then inhibits the kinase activity of MTORC1. Because FKBP12-rapamycin does not bind to MTORC2 (Jacinto et al. 2004, Sarbassov et al. 2004), rapamycin was thought to inhibit only MTORC1. However, it has been shown that in many cell types, prolonged rapamycin treatment reduces MTORC2 activity to levels below those needed to maintain AKT/PKB activation (Sarbassov et al. 2006). Thus, rapamycin-mediated inhibition of MTORC2 might also contribute to the clinical effects of the drug, and this action must be considered when rapamycin is administered to patients.

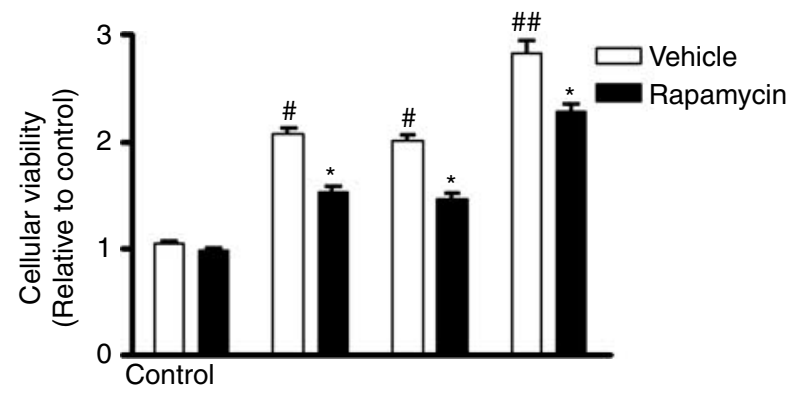
TSH
$(-)$
$(-)$
$(+)$
$(+)$
Insulin
$(-)$
$(+)$
$(-)$
$(+)$

Figure 6 Effect of rapamycin on PCCL3 cell viability. PCCL3 cells were treated for $48 \mathrm{~h}$ in the presence or in the absence of TSH $(1 \mathrm{mU} / \mathrm{ml})$, insulin $(10 \mu \mathrm{g} / \mathrm{ml})$, and $0 \cdot 2 \%$ FBS. Cells were starved for $72 \mathrm{~h}$ without TSH and insulin before the treatments. After $48 \mathrm{~h}$ of treatments, cell viability was determined by MTT assay. Values represent the results of three independent experiments related to control (untreated cells). Values are expressed as mean \pm S.E.M. $(n=12)$. ${ }^{\sharp} P<0.05$ versus control (without rapamycin). ${ }^{\#} P<0 \cdot 05$ versus control, TSH, and insulin treatments (without rapamycin). $* P<0.05$ vehicle versus rapamycin. 


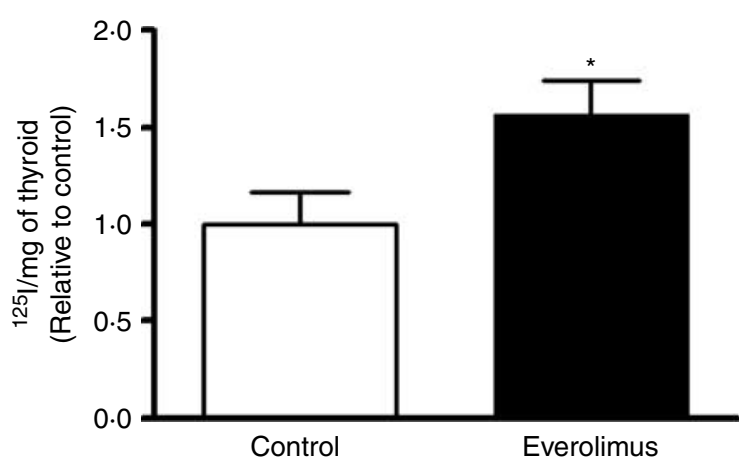

Figure 7 Effect of everolimus on iodide uptake by the thyroid gland in vivo. Male Wistar rats received four oral doses $(5 \mathrm{mg} / \mathrm{kg}$. b.w. each one). Everolimus was administered by oral gavage at four doses of $5 \mathrm{mg} / \mathrm{kg}$ body weight, 24, 8, 4, and $2 \mathrm{~h}$ before radioiodide administration, totaling $20 \mathrm{mg} / \mathrm{kg}$ body weight in $24 \mathrm{~h}$. Then, animals received $\left[{ }^{125} \mathrm{I}\right] \mathrm{Nal}(3700 \mathrm{~Bq}$, i.p., Amersham) 15 min prior to decapitation. Thyroids were weighted, and radioactivity was determined in a gamma-counter. lodide uptake was related to thyroid weight and expressed as relative to control values. Results were expressed as mean \pm s.E.M. (control $n=8$, everolimus $n=8$ ). $* P<0 \cdot 05$ versus control.

Our results suggest that in PCCL3 cells, rapamycin can inhibit not only MTORC1, but also MTORC2. We observed that rapamycin decreased AKT Ser473 phosphorylation that was stimulated by TSH. However, it has been previously shown that AKT inhibition, using an AKT1/AKT2 selective inhibitor (AKTi1/2), is not able to modulate neither iodide uptake nor Nis (listed as Slc5a 5 in the MGI Database) mRNA levels in FRTL-5 cells (Kogai et al. 2008). Thus, it is possible that AKT-independent pathways could also stimulate MTOR. Moreover, as we know that MTORC2 activates AKT, it suggests that MTORC2 probably does not affect NIS function or expression, even though it might influence cell viability. Further studies are needed in order to evaluate the role of MTORC2 in thyroid cell physiology.

Rapamycin could be a useful antitumor agent, as previously suggested (reviewed by Guertin \& Sabatini (2005)). The drug decreases the proliferation rate of many cancer cell lines, promotes apoptosis in some cancer lines, usually in combination with another agent; and lastly, it has antiangiogenic properties. These findings have led to the current interest in the potential use of rapamycin and its analogs for the treatment of human cancers. We observed that MTOR inhibition is able to significantly decrease cellular viability in the presence of insulin and TSH, an effect that might be useful in thyroid cancer management. In addition, our results show that insulin is as important for cell viability as TSH in the concentrations used, and that there is a synergistic effect between TSH and insulin in the regulation of cell viability, as previously described for cell proliferation and DNA synthesis (Roger et al. 1987). In fact, it has been shown that TSH proliferative signaling is conveyed through the MTOR kinase in vivo (Brewer et al. 2007). These authors have shown that MTOR/S6K1/S6 axis becomes hyperactive during chronic TSH stimulation. Furthermore, specific inhibition of MTOR activity by the rapamycin analog RAD001 (everolimus) abolishes the phosphorylation of p70 S6K (also called, S6K1), restoring normal proliferation rate. Chronic PI3K activation by the tissue-specific deletion of the Pten gene results in increased proliferation of thyroid follicular cells, which leads to thyroid hyperplasia and adenoma. Mice with inactivating mutation in Pten show increased thyroid cell proliferation rate which is inhibited by RAD001 (Yeager et al. 2008). It has recently been shown that cell lines with genetic alterations in the PI3K/AKT pathway are sensible to MTOR inhibition (Liu et al. 2009). Even in anaplastic thyroid cancer, the most aggressive thyroid malignance, RAD001 decreases cell proliferation (Papewalis et al. 2009). We have shown herein that rapamycin reduces cell viability; however, further studies are necessary to clarify whether this effect is due to an antiproliferative or proapoptotic action of rapamycin, or both.

Since MTOR inhibitors are under investigation for the therapy of other types of cancer, our study opens the question whether these drugs could also be useful for advanced thyroid cancer, probably in combination with radioiodine therapy. We have shown that everolimus, a rapamycin analog, was able to increase iodide uptake in normal rat thyroid in vivo, suggesting that it could also increase radioiodide uptake in thyroid cancer. Therefore, our data suggest that MTOR inhibitors might be useful to treat thyroid cancer in two aspects: increasing iodide uptake, what could improve the efficacy of radioiodine therapy, and decreasing tumor cell viability. However, it is important to notice that our study was conducted using normal thyroid cell line and rat normal thyroid, so further experiments are necessary in order to elucidate if these effects would also occur in thyroid cancer cells.

We conclude that MTOR kinase plays a key role in the control of thyroid iodide uptake and cell viability regulated by TSH and insulin. In view of the results presented here, we can conclude that TSH is able to activate both MTOR complexes: MTORC1 and MTORC2 in the thyroid PCCL3 cell line. Future studies will be focused on the identification of the specific MTOR complex that mediates downregulation of thyroid iodide uptake.

\section{Declaration of interest}

The authors declare that there is no conflict of interest that could be perceived as prejudicing the impartiality of the research reported.

\section{Funding}

This work was supported by grants from $\mathrm{CNPq}$ /Neoplasias, CNPq Universal, FAPERJ/SUS, and FAPERJ/Pensa Rio. ECLS, ÁSPF, WMOB, and BMA were recipients of fellowships from CNPq and CAPES. 


\section{Acknowledgements}

We would like to thank Prof. Roberto Di Lauro for providing anti-rat NIS antibody and the PCCL3 cells. We are also grateful for the technical assistance of Advaldo Nunes Bezerra, José Humberto de Abreu, Maria Aparecida de Oliveira Domingos, Norma Lima de Araújo Faria, and Wagner Nunes Bezerra.

\section{References}

Alessi DR, Andjelkovic M, Caudwell B, Cron P, Morrice N, Cohen P \& Hemmings BA 1996 Mechanisms of activation of protein kinase B by insulin and IGF-1. EMBO Journal 15 6541-6551.

Bellacosa A, Kumar CC, Di Cristofano A \& Testa JR 2005 Activation of Akt kinases in cancer: implications for therapeutical targeting. Advances in Cancer Research 94 29-86.

Brewer C, Yeager N \& Di Cristofano A 2007 Thyroid-stimulating hormone-initiated proliferative signals converge in vivo on the $\mathrm{mTOR}$ kinase without activating Akt. Cancer Research 67 8002-8006.

Cass LA, Summers SA, Prendergast GV, Backer JM, Birnbaum MJ \& Meinkoth JL 1999 Protein kinase A-dependent and -independent signaling pathways contribute to cyclic AMP-stimulated proliferation. Molecular Cell Biology 19 5882-5891.

Coulonval K, Vandeput F, Stein RC, Kozma SC, Lamy F \& Dumont JE 2000 Phosphatidylinositol 3-kinase, protein kinase B and ribosomal S6 kinases in the stimulation of thyroid epithelial cell proliferation by cAMP and growth factors in the presence of insulin. Biochemical Journal 348 351-358.

Dai G, Levy O \& Carrasco N 1996 Cloning and characterization of the thyroid iodide transporter. Nature 379 458-460.

Dohan O, De la Vieja A, Paroder V, Riedel C, Artani M, Reed M, Ginter CS \& Carrasco N 2003 The sodium/iodide symporter (NIS): characterization, regulation, and medical significance. Endocrine Reviews 24 48-77.

Ferreira AC, Lima LP, Araújo RL, Muller G, Rocha RP, Rosenthal D \& Carvalho DP 2005 Rapid regulation of thyroid sodium-iodide symporter activity by thyrotropin and iodine. Journal of Endocrinology 184 69-76.

Garcia B \& Santisteban P 2002 PI3K is involved in the IGF-1 inhibition of TSH-induced sodium/iodide symporter gene expression. Journal of Endocrinology 16 342-352.

Guertin DA \& Sabatini DM 2005 An expanding role for mTOR in cancer. Trends in Molecular Medicine 11 353-361.

Hresko RC \& Mueckler M 2005 mTOR.RICTOR is the Ser 473 kinase for Akt/protein kinase B in 3T3-L1 adipocytes. Journal of Biological Chemistry $28040406-40416$.

Inoki K, Li Y, Zhu T, Wu J \& Guan KL 2002 TSC2 is phosphorylated and inhibited by Akt and suppresses mTOR signaling. Nature Cell Biology 4 648-657.

Jacinto E, Loewith R, Schmidt A, Lin S, Ruegg MA, Hall A \& Hall MN 2004 Mammaliam TOR complex 2 controls the actin cytoskeleton and is rapamycin insensitive. Nature Cell Biology 6 1122-1128.

Kimura T, Van Keymeulen A, Golstein J, Fusco A, Dumont JE \& Roger PP 2001 Regulation of thyroid cell proliferation by TSH and other factors: a critical evaluation of in vitro models. Endocrine Reviews 22 631-656.

Kogai T, Sajid-Crockett S, Newmarch LS, Liu YY \& Brent GA 2008 Phosphoinositide-3-kinase (PI3K) inhibition induces sodium/iodide symporter expression (NIS) in rat thyroid cells and human pappilary cancer cells. Journal of Endocrinology 199 243-252.

Laglia G, Zeiger MA, Leipricht A, Caturegli P, Levine MA, Kohn LD \& Saji M 1996 Increased cyclic adenosine $3^{\prime}, 5^{\prime}$-monophosphate inhibits $G$ protein-coupled activation of phospholipase C in rat FRTL-5 thyroid cells. Endocrinology 137 3170-3176.

Liu D, Hou P, Liu Z, Wu G \& Xing M 2009 Genetic alterations in the phosphoinositide 3-kinase/Akt signaling pathway confer sensitivity of thyroid cancer cells to therapeutic targeting of Akt and mammalian target of rapamycin. Cancer Research 69 7311-7319.

Manning BD, Tee AR, Longsdon MN, Blenis J \& Cantley LC 2002 Identification of the tuberous slerosis complex- 2 tumor suppressor gene product tuberin as a target of the phosphoinositide 3-kinase/Akt pathway. Molecular Cell 10 151-162.
Mazaferri EL 2000 Carcinoma of the follicular epithelium. In Thyroid: a Fundamental and Clinical Text. edn 8, pp 904-930. Eds L Braverman \& R Utiger. New York: Lippincott Williams \& Wilkins.

Medina DL, Toro MJ \& Santisteban P 2000 Somatostatin interferes with thyrotropin-induced $\mathrm{G}_{1}-\mathrm{S}$ transition mediated by cAMP-dependent protein kinase and phosphatidylinositol 3-kinase. Involvement of RhoA and cyclin E cyclin dependent kinase 2 complexes. Journal of Biological Chemistry 275 15549-15556.

Navé BT, Ouwens M, Withers DJ, Alessi DR \& Shepherd PR 1999 Mammalian target of rapamycin is a direct target for protein kinase B: identification of a convergence point for opposing effects of insulin and amino-acid deficiency on protein translation. Biochemical Journal 344 421-431.

Papewalis C, Wuttke M, Schinner S, Willenberg HS, Baran AM, Scherbaum WA \& Schott M 2009 Role of the novel mTOR inhibitor RAD001 (everolimus) in anaplastic thyroid cancer. Hormone and Metabolic Research $\mathbf{4 1}$ $752-756$.

Riedel C, Levy O \& Carrasco N 2001 Post-transcriptional regulation of the sodium/iodide symporter by thyrotropin. Journal of Biological Chemistry 276 21458-21463.

Roger PP, Servais P \& Dumont JE 1987 Induction of DNA synthesis in dog thyrocytes in primary culture: synergistic effects of thyrotropin and cyclic AMP with epidermal growth factor and insulin. Journal of Cellular Physiology $13058-67$.

Sarbassov DD, Ali SM, Kim DH, Quertin DA, Latek RR, ErdjumentBromage H, Tempst P \& Sabatini DM 2004 Rictor, a novel binding partner of mTOR, defines a rapamycin-insensitive and raptor-independent pathway that regulates the cytoesqueleton. Current Biology 14 1296-1302.

Sarbassov DD, Ali SM \& Sabatini DM 2005a Growing roles for the mTOR pathway. Current Opinion in Cell Biology 17 596-603.

Sarbassov DD, Quertin DA, Ali SM \& Sabatini DM 2005b Phosphorylation and regulation of Akt/PKB by the rictor-mTOR complex. Science $\mathbf{3 0 7}$ 1098-1101.

Sarbassov DD, Ali SM, Sengupta S, Sheen JH, Hsu PP, Bagley AF, Markhard AL \& Sabatini DM 2006 Prolonged rapamycin treatment inhibits mTORC2 assembly and Akt/PKB. Molecular Cell 22 159-168.

Suh JM, Song JH, Kim DH, Kim H, Chung HK, Hwang JH, Kim JM, Hwang ES, Chung J, Han JH et al. 2003 Regulation of the phosphatidylinositol 3-kinase, Akt/protein kinase B, FRAP/mammalian target of rapamycin, and ribosomal S6 kinase 1 signaling pathways by thyroidstimulating hormone (TSH) and stimulating type TSH receptor antibodies in the thyroid gland. Journal of Biological Chemistry 278 21960-21971.

Unterholzner S, Willhauck MJ, Cengic N, Schütz M, Göke B, Morris JC \& Spitzweg C 2006 Dexamethasone stimulation of retinoic acid-induced sodium iodide symporter expression and cytotoxicity of 131-I in breast cancer cells. Journal of Clinical Endocrinology and Metabolism 91 69-78.

Vassart G \& Dumont JE 1992 The thyrotropin receptor and the regulation of thyrocyte function and growth. Endocrine Reviews 13 596-611.

Venkataraman GM, Yatin M, Marcinek R \& Ain KB 1999 Restoration of iodide uptake in dedifferentiated thyroid carcinoma: relationship to human $\mathrm{Na}^{+} / \mathrm{I}^{-}$symporter gene methylation status. Journal of Clinical Endocrinology and Metabolism 84 2449-2457.

Weiss SJ, Philp NJ, Ambesi-Impiobato FS \& Grollman EF 1984 Thyrotropin stimulated iodide transport mediated by adenosine $3^{\prime}, 5^{\prime}$-monophosphate and dependent on protein synthesis. Endocrinology 114 1099-1107.

Yeager N, Brewer C, Cai KQ, Xu XX \& Di Cristofano A 2008 Mammalian target of rapamycin is the key effector of phosphatidyliositol-3$\mathrm{OH}$-initiated proliferative signals in the thyroid follicular epithelium. Cancer Research 68 444-449.

Zaballos MA, Garcia B \& Santisteban P 2008 G $\beta \gamma$ dimers released in response to thyrotropin activate phosphoinositide 3-kinase and regulate gene expression in thyroid cells. Molecular Endocrinology 22 1183-1199.

Received in final form 8 April 2010

Accepted 14 April 2010

Made available online as an Accepted Preprint 14 April 2010 